\title{
Las lenguas indígenas u originarias del Perú en el internet
}

\author{
Gerardo Manuel Garcia Chinchay ${ }^{1}$ \\ Mercedes Elvira Mere Chávez ${ }^{2}$
}

\begin{abstract}
Resumen
En este artículo se muestran diferentes iniciativas que se han realizado en Perú a favor de las lenguas indígenas u originarias peruanas en su ingreso al mundo de internet. Dichas iniciativas, que pueden provenir del Estado, de las entidades privadas o del activismo de sus hablantes, tienen como objetivo crear herramientas tecnológicas que permitan el acceso a información específica por parte de usuarios de estas lenguas; además las iniciativas se encuentran respaldadas por una legislación vigente. Este trabajo académico se sitúa teóricamente en las propuestas de Crystal (2006) y Danet y Herring (2007), quienes señalan que la presencia de lenguas en internet es una oportunidad de desarrollo de la propia lengua. Finalmente, el artículo concluye con una breve evaluación de todas las iniciativas encontradas.
\end{abstract}

Palabras clave: Lenguas indígenas peruanas. Internet. Herramientas tecnológicas.

\section{Abstract}

The aim of this paper is to show some of the initiatives that began in Peru in favor of the insertion of peruvians indigenous languages into the internet world. These initiatives can be approaches from the public sector, the private sector or the activism of the language community itself to create technological tools that allow the speakers to access to specific information in indigenous languages, since all of these are supported by current legislation. This paper is theoretically settled on the approaches of Crystal (2006) and Danet and Herring (2007), whom state the presence of languages on the internet are a development opportunity to languages themselves. Finally, the paper concludes with a brief evaluation of the initiatives that were found and described.

Keywords: Peruvian indigenous languages. Internet. Technological tools.

\section{Introducción}

Según datos del Atlas UNESCO de las lenguas del mundo en peligro y la plataforma Ethnologue, existen en el mundo entre 6 y 7 mil lenguas, de las cuales más del $50 \%$ se hablan en los continentes de África, Asia y América. Esta diversidad lingüística es asimétrica ya que el 50\% de la población mundial habla alrededor de 50 lenguas y el otro 50\% habla aproximadamente 6.950 lenguas. Así, hay países que poseen poca variedad lingüística, es decir, que en estos se habla un número reducido

\footnotetext{
1 Maestro en Letras: Estudios Linguísticos. Universidad Nacional Federico Villarreal. E-mail: ggarcia@unfv.edu.pe.

2 Estudiante de Linguística. Universidad Nacional Federico Villarreal. E-mail: mercedesmerebtr@gmail.com.
} 
de lenguas y dialectos, y otros en donde se hablan más de 500 lenguas; tal es el caso de Singapur en donde se hablan 840 lenguas 3 . En el Perú se han identificado hasta el momento tres tipos de lenguas: el castellano, que es la lengua oficial del estado peruano; la lengua de señas peruana ${ }^{4}$ y 48 lenguas indígenas u originarias (MINISTERIO DE EDUCACIÓN, 2018) habladas por más de 4 millones de personas a nivel nacional, como se detalla en la Tabla 1. Sobre estas lenguas, la realidad también es asimétrica ya que existen lenguas indígenas $u$ originarias con aproximadamente tres millones de hablantes, como el quechua, y en el caso extremo negativo, lenguas con un solo hablante fluido, como el taushiro5. Dada la compleja realidad lingüística peruana, en este artículo sólo nos dedicaremos a reflexionar sobre la presencia de las lenguas indígenas peruanas en internet por medio de algunas de las herramientas tecnológicas desarrolladas por entidades públicas, privadas y los propios hablantes.

\begin{tabular}{|c|c|c|}
\hline $\mathrm{N}^{\circ}$ & $\begin{array}{c}\text { Lenguas indígenas u } \\
\text { originarias }\end{array}$ & $\begin{array}{c}\text { TOTAL población de } 3 \text { y más } \\
\text { años de edad de lengua } \\
\text { materna indígena }\end{array}$ \\
\hline \multicolumn{2}{|c|}{$\begin{array}{c}\text { TOTAL de hablantes de lenguas } \\
\text { indígenas u originarias a nivel nacional }\end{array}$} & $4,477,195$ \\
\hline 1 & quechua & $3,805,531$ \\
\hline 2 & aimara & 450,010 \\
\hline 3 & ashaninka & 73,567 \\
\hline 4 & awajún & 56,584 \\
\hline 5 & ahipibo-konibo & 34,152 \\
\hline 6 & shawi & 17,241 \\
\hline 7 & matsigenka & 6,629 \\
\hline 8 & ticuna & 4,290 \\
\hline 9 & nomatsigenga & 3,895 \\
\hline 10 & achuar & 3,809 \\
\hline 11 & wampis & 3,569 \\
\hline 12 & yine & 2,680 \\
\hline 13 & kakataibo & 1,553 \\
\hline 14 & matsés & 1,366 \\
\hline 15 & urarina & 1,301 \\
\hline 16 & kukama kukamiria & 1,185 \\
\hline
\end{tabular}

\footnotetext{
3 Datos obtenidos de: https://www.ethnologue.com/guides/countries-most-languages

4 Declarada lengua oficial peruana mediante la Ley $n^{\circ} 29535$.

5 Lengua hablada en Loreto, Perú por el Sr. Amadeo Garcia. (MINISTERIO DE CULTURA, 2018)
} 


\begin{tabular}{|c|c|c|}
\hline 17 & yanesha & 1,142 \\
\hline 18 & cashinahua & 1,074 \\
\hline 19 & kandozi-chapra & 877 \\
\hline 20 & yagua & 712 \\
\hline 21 & harakbut & 664 \\
\hline 22 & secoya & 638 \\
\hline 23 & yaminahua & 574 \\
\hline 24 & sharanahua & 573 \\
\hline 25 & jaqaru & 448 \\
\hline 26 & murui-muinani & 416 \\
\hline 27 & amahuaca & 328 \\
\hline 28 & kakinte & 273 \\
\hline 29 & nahua & 232 \\
\hline 30 & ese eja & 212 \\
\hline 31 & kawki & 132 \\
\hline 32 & maijiki & 121 \\
\hline 33 & arabela & 118 \\
\hline 34 & kapanawa & 117 \\
\hline 35 & shiwilu & 53 \\
\hline 36 & ocaina & 44 \\
\hline 37 & iskonawa & 22 \\
\hline 38 & omagua & 3 \\
\hline 39 & chamicuro (*) & 23 \\
\hline 40 & muniche (*) & 8 \\
\hline 41 & iñapari (*) & 4 \\
\hline 42 & taushiro (*) & 2 \\
\hline 43 & resígaro (*) & 1 \\
\hline 44 & asheninka (**) & 8,774 \\
\hline 45 & bora (**) & 748 \\
\hline 46 & ikitu (米) & 519 \\
\hline 47 & madija (**) & 417 \\
\hline 48 & nanti ${ }^{6}$ (**) & 250 \\
\hline
\end{tabular}

(*) El número de hablantes de esta lengua es aproximado, según datos del Ministerio de Educación (**) Información aproximada que se encuentra en proceso de actualización Tabla 1. Población por lengua materna indígena.

Fuente: Base de Datos de Pueblos Indígenas u Originarias (BDPI).

\section{Fundamentación teórica}

\subsection{Las lenguas y el internet}

\footnotetext{
${ }^{6}$ En el proceso de normalización del alfabeto de esta lengua, los hablantes decidieron denominarla como matsigenka montetokunirira en vez de nanti (Resolución Ministerial № 706-2018-MINEDU).
} 
Este artículo sigue la línea teórica propuesta por David Crystal en Language and the Internet (2006) en la que afirma que la lengua tiene en internet una ventana de posibilidades de desarrollo, tanto escrito como oral. Al respecto, señala (CRYSTAL, 2006, p. 216):

La Web es un medio ecléctico y esto se puede observar también en su inclusividad multilingüística. No solo ofrece un lugar para todos los estilos lingüísticos dentro de una lengua, sino que también ofrece un lugar para todas las lenguas - una vez que sus comunidades tengan una tecnología informática funcional. (Traducción hecha por los autores7)

La aparición de internet ha aportado grandes avances en cuanto a la actualización de hardware y software para el almacenamiento y recuperación de información, así como para la interconexión de dispositivos electrónicos, masificando el uso de estos y, actualmente, el acceso a internet es posible desde artefactos como computadoras y tablets (MARTINEZ y VALDEZ, 2014). Dado que el desarrollo del internet tiene orígenes angloparlantes, la creación de plataformas tecnológicas en lenguas que presentan gran cantidad de variedades y que comparten pocos o ningunos rasgos lingüísticos con el inglés ha significado una gran dificultad. Así como explica Paolillo en Danet y Herring (2007, p. 424):

La baja diversidad lingüística facilita potencialmente el acceso a Internet, ya que un pequeño número de soluciones tecnológicas estandarizadas pueden servir a grandes comunidades lingüísticas. Las regiones y los países con una mayor diversidad lingüística necesitarían soluciones personalizadas, potencialmente caras, para un gran número de grupos de lenguas minoritarias. (Traducción hecha por los autores ${ }^{8}$ )

\footnotetext{
7 "The Web is an eclectic medium, and this is seen also in its multilinguistic inclusiveness. Not only does it offer a home to all linguistic styles within a language; it offers a home to all languages - once their communities have a functioning computer technology."

8 "Low linguistic diversity potentially facilitates Internet access, since a small number of standardized technological solutions can serve large language populations. Regions and countries with greater linguistic diversity would need potentially expensive customized solutions for a large number of minority language groups."
} 
Además, en la actual era de la globalización, “la instantaneidad que ofrece el servicio de Internet nos permite, además de acceder a información, poder responder a las solicitudes comunicacionales con nuestros interlocutores y poder publicar, también inmediatamente, información en cualquiera de sus formatos (texto, voz, video, imágenes, o la combinación de estos)" (MARTINEZ y VALDEZ, 2014, p. 128). Es a partir de estos argumentos que se vuelve clara la importancia de la existencia de herramientas tecnológicas en lenguas indígenas u originarias para permitir la comunicación y el acceso a información por sus hablantes. La existencia de estas herramientas se vuelve aún más crucial para la comunidad de hablantes pues, en la mayoría de los casos, también sirve para reforzar un sentido de identidad dentro de plataformas en internet que, como la globalización, tienden a homogeneizar y simplificar. Como señala Herring, citado en Danet y Herring (2007, p.7), “la elección de la lengua y el uso de la lengua son los medios principales para señalizar la identidad cultural en medios de comunicación mediados por computadora [...]" (Traducción hecha por los autores ${ }^{9}$ ).

Algunos autores (Cunliffe y Herring, 2005, citado en DANET y HERRING, 2007) también sugieren que estas herramientas informáticas podrían constituir una forma de contrarrestar la muerte de las lenguas, ya que “[...] con la globalización del internet, la presencia de otras lenguas [aparte del inglés] ha aumentado constantemente" $\left(\right.$ CRYSTAL, 2006, p. 216) ${ }^{10}$. Así, se ha podido reflejar la distribución de la presencia de lenguas no mayoritarias en el mundo a través de la existencia de periódicos, archivos y repositorios en la web que contienen información en dichas lenguas (CRYSTAL, 2006). Para Crystal, esta presencia se trataría del resultado de la gran ventaja que representa una página web pues "es el medio ideal para las lenguas minoritarias, dada la relativa economía y facilidad de crear una página web, comparado con el costo y la dificultad de conseguir una sección en un periódico o un programa o publicidad en radio 0 televisión" (CRYSTAL, 2006, p. 221)

\footnotetext{
9 "Indeed, language choice and language use are the primary means of signaling cultural identity in textbased CMC, which transcends geographical boundaries and in which physical and social cues are reduce." 10 "But with the Internet's globalization, the presence of other languages has steadily risen."

11 "It is the ideal medium for minority languages, given the relative cheapness and ease of creating a Web page, compared with the cost and difficulty of obtaining a newspaper page, or a programme or advertisement on radio or television."
} 


\subsection{Legislación internacional y nacional}

UNESCO elaboró la Declaración Universal sobre Diversidad Cultural (2001), documento donde se señalan recomendaciones importantes con respecto a las lenguas en peligro de extinción. Así, se especifica en el punto 10 del Anexo II que, para lograr los objetivos planteados en dicha declaración, es necesario “promover la diversidad lingüística en el ciberespacio y fomentar el acceso universal a través de la red global hacia toda la información en el ámbito público" (UNESCO, 2001, p.64). Asimismo, esta institución declaró el año 2019 como el Año Internacional de las Lenguas Indígenas, poniendo en la agenda internacional la importancia de promover el desarrollo de las lenguas originarias, así como su recuperación y fomentando su uso en todos los espacios sociales y culturales.

Por su parte, en la legislación peruana existen tres normas que son importantes para el desarrollo de las lenguas indígenas u originarias en el internet: la ley de Lenguas o Ley $n^{\circ} 29735$, el Reglamento de esta ley y la Política Nacional de Lenguas Originarias, Tradición Oral e Interculturalidad. En primer lugar, la Ley $n^{\circ} 29735$, Ley de Lenguas indigenas u originarias, promulgada el año 2011, establece en su artículo 4, inciso 1 , literal c) que es derecho de toda persona "Usar su lengua originaria en los ámbitos público y privado." Asimismo, en el artículo 12, literal e) se indica que “El Estado, a través de las instancias sectoriales correspondientes, garantiza la multifuncionalidad de las lenguas originarias y su calidad de patrimonio cultural inmaterial e integra su salvaguardia en los programas de planificación educativa, cultural y de investigación". En segundo lugar, en el artículo 21, inciso 3 del Reglamento de la Ley $n^{\circ} 29735$, Ley de lenguas indigenas u originarias, se establece que “El Ministerio de Cultura promueve e implementa aplicaciones de nuevas tecnologías, a través de convenios con entidades privadas que difundan información básica de las lenguas indígenas u originarias, así como otras aplicaciones de alto uso en las lenguas indígenas u originarias". 
Finalmente, la Política Nacional de Lenguas Originarias, Tradición Oral e Interculturalidad, aprobada por Decreto Supremo $\mathrm{n}^{\circ}$ 005-2017-MC, tiene por objetivo garantizar los derechos lingüísticos de los hablantes de lenguas indígenas u originarias en el ámbito nacional y establecer ejes y lineamientos orientados a fomentar el uso, promoción, recuperación y revitalización de las lenguas indígenas u originarias del Perú. El tercer eje plantea objetivos y lineamientos que buscan, entre otras cosas, promover e incentivar la elaboración y publicación de diccionarios, gramáticas, manuales en ediciones bilingües y accesibles, entre otros recursos, para el conocimiento de las lenguas indígenas u originarias peruanas.

3 Iniciativas de presencia digital de lenguas indígenas u originarias peruanas por parte de instituciones públicas

\subsection{Iniciativas públicas}

\subsubsection{Mapa Sonoro Estadístico de las Lenguas Indígenas y Originarias}

Es una plataforma virtual desarrollada el año 2015 por el Ministerio de Cultura del Perú con la finalidad de brindar información oficial, estadística y actualizada sobre las 48 lenguas indígenas u originarias que se hablan a lo largo del territorio peruano. Esta plataforma permite escuchar las lenguas a través de audios con cantos tradicionales, frases y presentaciones en la lengua de los pueblos indígenas u originarios presentes en los diferentes departamentos del país ${ }^{12}$. El programa es usado no solo por escolares, universitarios y estudiosos de las lenguas indígenas u originarias del país, sino también por funcionarios y servidores públicos, siendo considerada una herramienta de gestión indispensable. De ahí que esta iniciativa fue ganadora del Trofeo Jaqaru 2015, otorgado por el pueblo Jaqaru, y del Premio a las Buenas Prácticas en Gestión Pública 2015. Recientemente, el Ministerio de Cultura, a través de la Dirección de Lenguas Indígenas,

\footnotetext{
12 Se puede acceder al Mapa Sonoro Estadistico de las Lenguas Indigenas y Originarias a través del siguiente enlace: https://geoportal.cultura.gob.pe/mapa/perfil/lenguas
} 


\section{LIINGUATEC}

ha desarrollado una aplicación disponible para Android e iOS con la finalidad que más ciudadanos puedan hacer uso de esta herramienta.

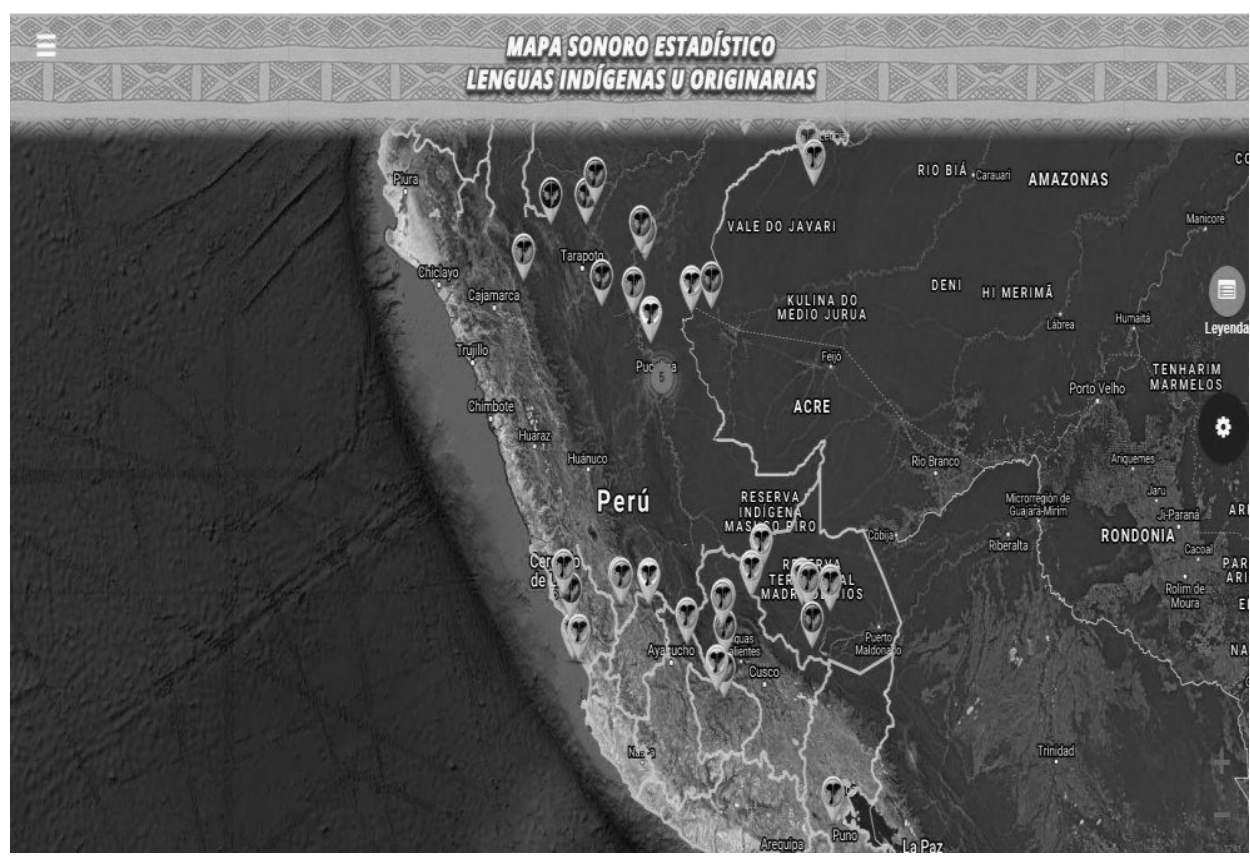

Figura 1. Plataforma del Mapa Sonoro Estadístico de las Lenguas Indígenas y Originarias. Fuente: Ministerio de cultura (2015).

\subsubsection{Aplicación Uyariy}

Esta aplicación, cuyo significado en lengua quechua es "escuchar", ha sido desarrollado por el Ministerio de Cultura de manera coordinada y conjunta con el Registro Nacional de Identificación y Estado Civil (RENIEC), y fue presentada oficialmente en el marco de la conmemoración del Día de la Lengua Materna del presente año (2020). La herramienta informática cuenta con frases de uso frecuente por parte de los registradores al prestar los servicios de identificación y registro civil tanto en español como en quechua, permitiendo conocer cómo se dicen y qué significan a través de audios y transcripciones en ambas lenguas, mejorando así la atención que se brinda a los ciudadanos peruanos hablantes de quechua. Una vez culminadas las actualizaciones de la aplicación, se empezó a probar en RENIEC con el objetivo de extender progresivamente su uso en este organismo registral. Actualmente, está 
disponible para su descarga en celulares y tabletas $^{13}$ (PERÚ 21, 2020; ANDINA AGENCIA PERUANA DE NOTICIAS, 2020).

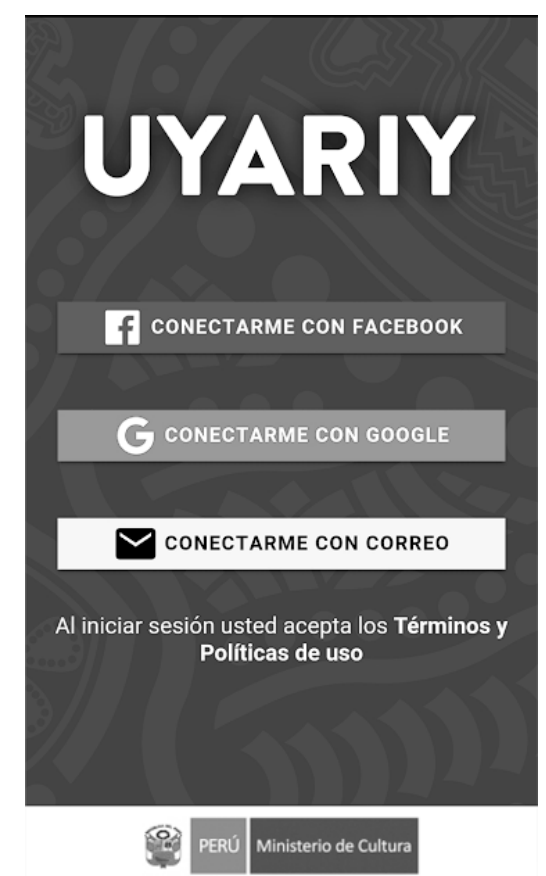

Figura 2. Aplicación Uyariy.

Fuente: Perú 21 (2020).

\subsubsection{Aplicación Habla Q̨uechua}

Habla Quechua es una aplicación creada por la Comisión de Promoción del Perú para la Exportación y el Turismo (PROMPERÚ) del Ministerio de Comercio Exterior y Turismo. Fue lanzada en el año 2013 como parte de la campaña nacional Representantes de lo Nuestro y ha sido desarrollada con el fin de que las personas puedan aprender palabras y expresiones en quechua ya que, a través de gráficos y audios, difunde vocabulario de la lengua quechua en su variedad cusco-collao de manera entretenida y didáctica. Esta aplicación ganó en el año 2015 el premio App

\footnotetext{
${ }^{13}$ Se puede descargar la aplicación Uyariy en el siguiente enlace: https://play.google.com/store/apps/details?id=pe.gob.cultura. app.uyariy
} 
Innovation (MINCETUR, 2015) y se encuentra disponible para su descarga en Google Play ${ }^{14}$.

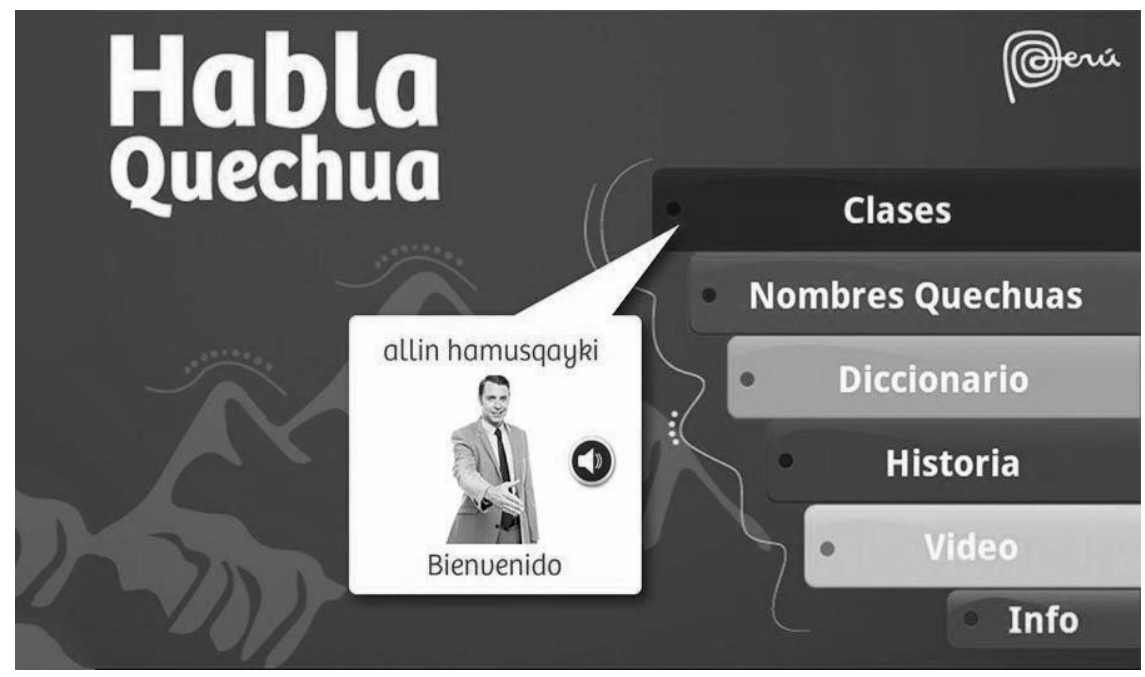

Figura 3. Aplicación Habla Quechua.

Fuente: Ministerio de comercio exterior y turismo (2013).

\subsubsection{Diccionarios Virtuales al Bicentenario}

Este proyecto fue iniciado en el 2016 por el Ministerio de Cultura con la meta de elaborar diccionarios semibilingües ${ }^{15}$ de las lenguas indígenas u originarias peruanas con miras al 2021, año en que se celebrará 200 años de independencia del Perú. Estos diccionarios son plataformas interactivas con imágenes, audios e información cultural y lingüística. Se inició este proyecto a partir del desarrollo y lanzamiento oficial en el año 2017 del Diccionario Virtual de la Lengua Yine ${ }^{16}$, lengua hablada en los departamentos peruanos de Cusco, Ucayali, Madre de Dios y Loreto. Actualmente, la plataforma se encuentra en actualización para su posterior acceso desde internet. Igualmente, se viene desarrollando el Diccionario Virtual de la lengua harakbut wachiperi, herramienta que contribuirá a la visibilización de esta lengua hablada en la

\footnotetext{
14 Se puede descargar la aplicación Habla Quechua en el siguiente enlace: https://play.google.com/store/apps/details?id=info.peru.habla.quechua.perughl=en_US

${ }^{15}$ Con definiciones y ejemplos en la propia lengua indígena u originaria y con traducción al castellano.

16 Más información sobre el lanzamiento del Diccionario Virtual de la Lengua Yine: https://www.culturacusco.gob.pe/noticia/imagen/cultura-cusco-presento-diccionario-enciclopedicovirtual-de-la-lengua-yine-yami/
} 
amazonia de Cusco, así como al crecimiento del proyecto en general (DIRECCIÓN DESCONCENTRADA DE CULTURA DE CUSCO, 2017).

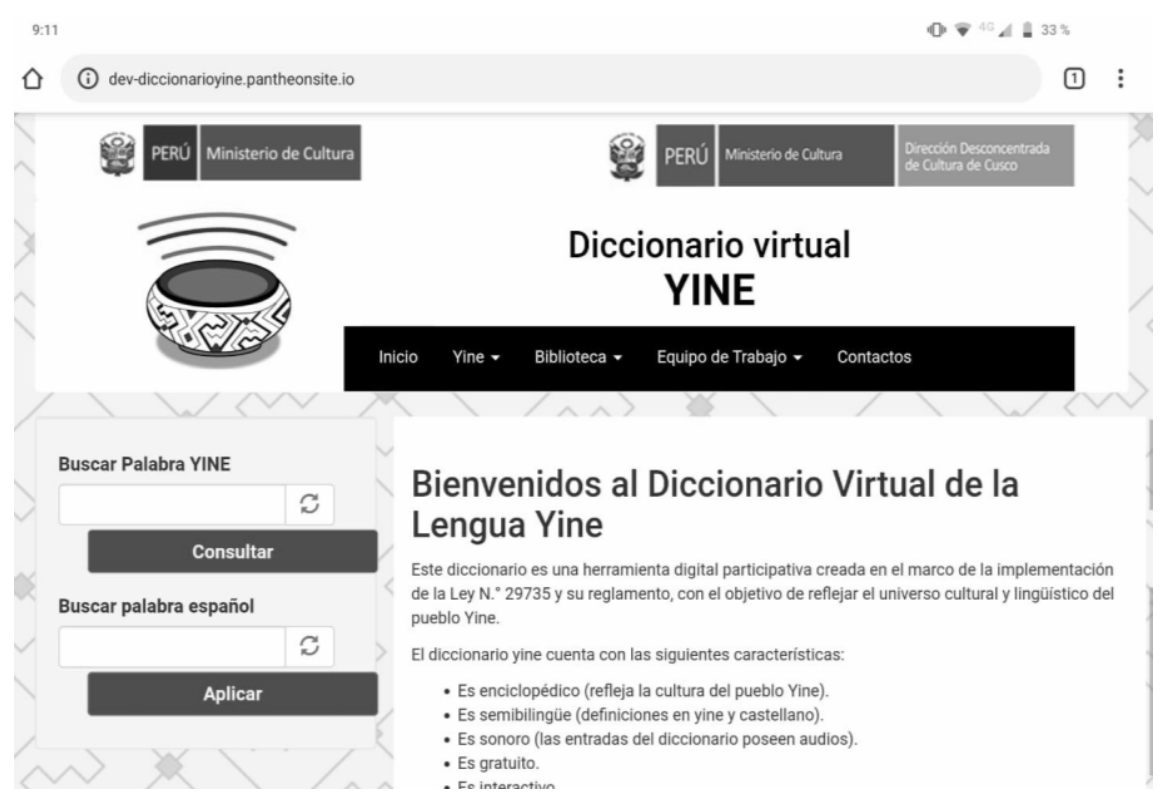

Figura 4. Sección de inicio del Diccionario virtual de la lengua yine.

Fuente: Ministerio de cultura (2017).

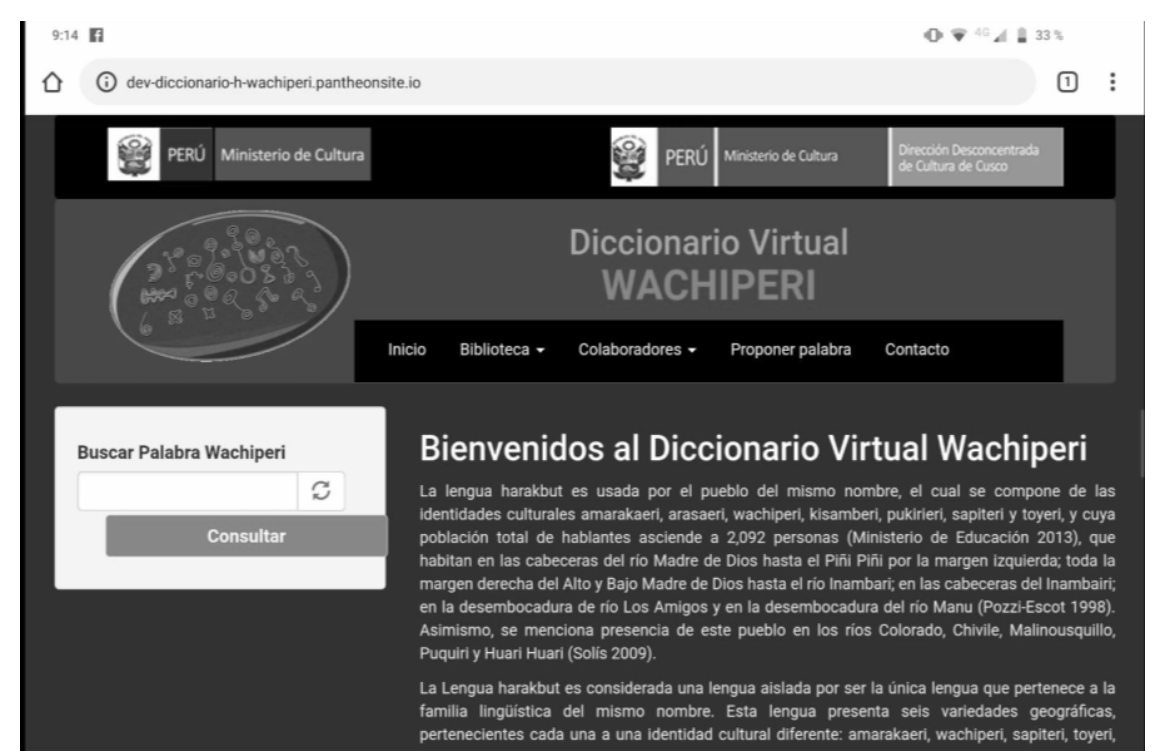

Figura 5. Sección de inicio del Diccionario virtual de la lengua harakbut wachiperi. Fuente: Ministerio de cultura (en desarrollo). 
3.1.5 Sistema digital para el aprendizaje PerúEduca - MINEDU

PerúEduca es una plataforma digital del Ministerio de Educación (MINEDU) que brinda servicios como cursos y materiales virtuales con el objetivo de capacitar a la comunidad escolar y docente del sector educativo ${ }^{17}$. Periódicamente en la plataforma se brindan cursos virtuales de escritura en lenguas indígenas u originarias del Perú dirigidos a docentes de Educación Intercultural Bilingüe, a hablantes de estas lenguas y al público en general, así como materiales educativos en distintas lenguas indígenas u originarias.

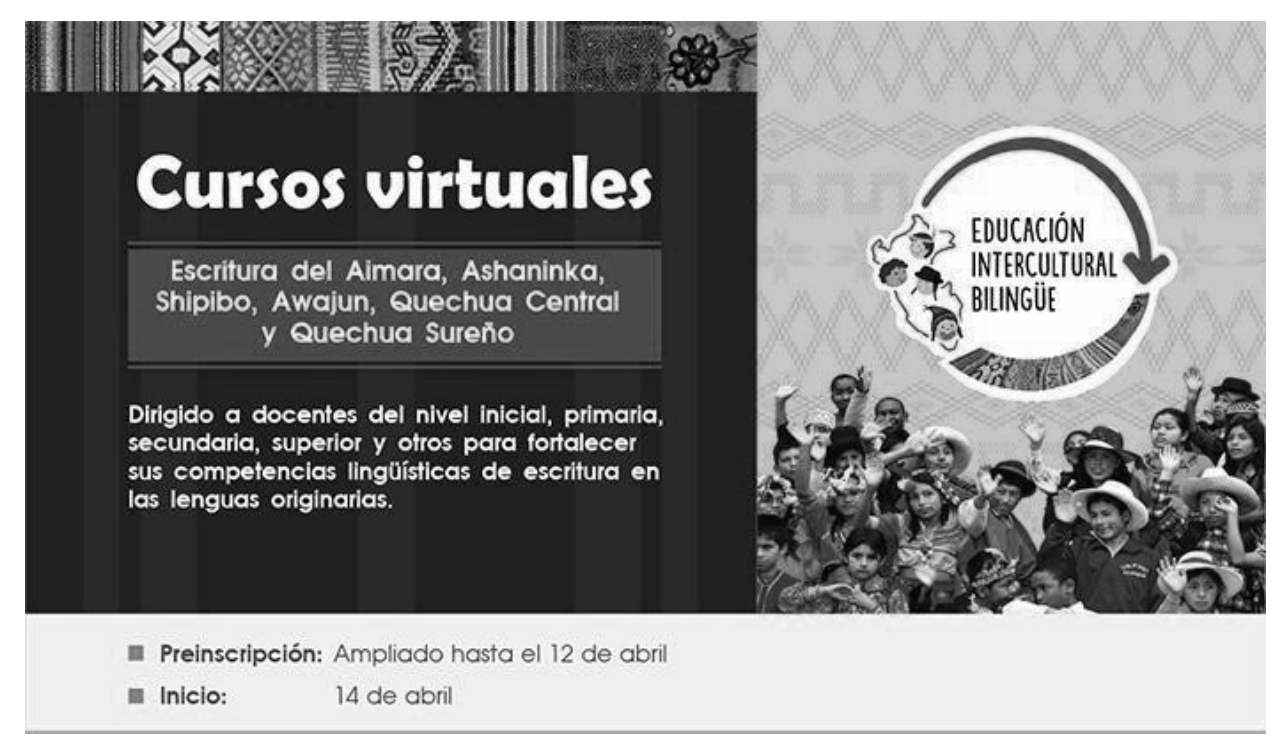

Figura 6. Aviso sobre cursos virtuales de escritura de lenguas indígenas u originarias en la plataforma PerúEduca.

Fuente: Ministerio de Educación.

3.2 Iniciativas privadas

3.2.1 Traductor morfológico quechua / castellano - Hinantin

Hinantin es un grupo de investigación asentado en Cusco y creado en 2015 con el fin de fomentar la investigación y desarrollo de software para, de esta manera,

17 Se puede acceder a la plataforma PerúEduca a través del siguiente enlace: http://www.perueduca.pe/inicio

LínguaTec, Instituto Federal de Educação, Ciência e Tecnologia do Rio Grande do Sul, Bento Gonçalves v. 5 , n. 1, p. 109-136, jun. 2020. 
promover el uso de las lenguas indígenas u originarias peruanas. Entre los productos de impacto que ha desarrollado este equipo tienen un Conversor de texto a voz en quechua, un Corrector ortográfico en línea (quechua) y un Traductor morfológico quechua - castellano ${ }^{18}$.

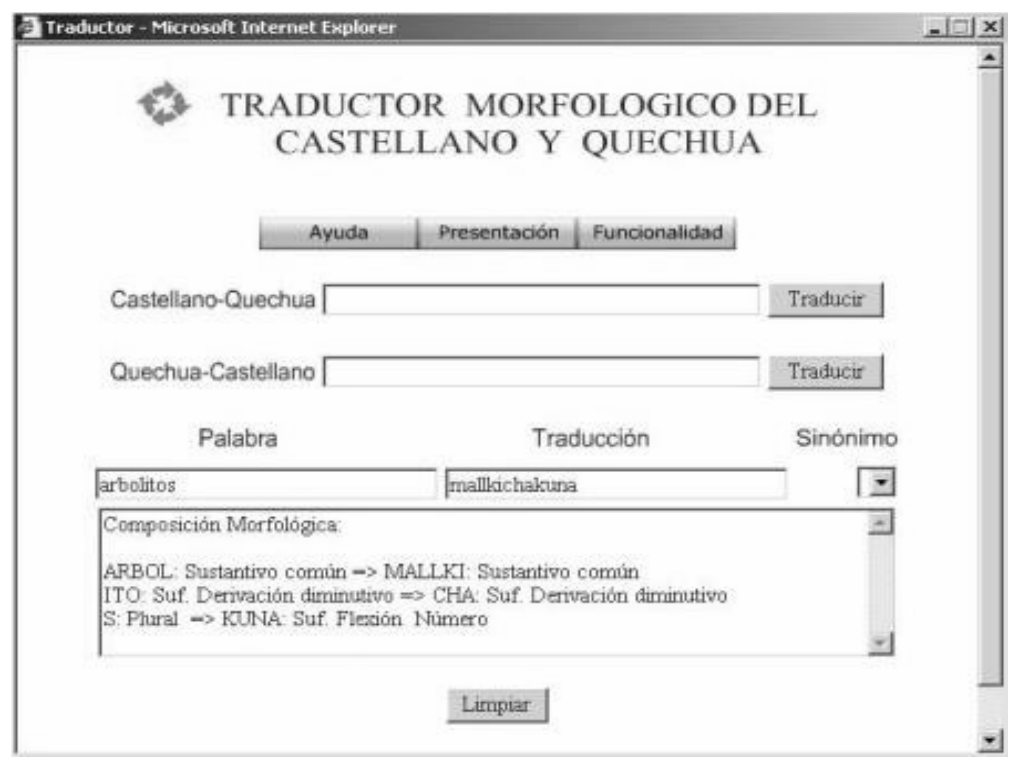

Figura 7. Traductor morfológico quechua - castellano. Fuente: Hinantin (2015).

3.2.2 Aplicaciones en lenguas amazónicas - Instituto de Investigaciones de la Amazonía Peruana

El Instituto de Investigaciones de la Amazonía Peruana (IIAP) en colaboración con la Universidad Nacional de la Amazonía Peruana creó cinco aplicaciones móviles para revitalizar las lenguas amazónicas ticuna ${ }^{19}(B u x u ̈), k^{2} a n d o z i^{20}(K a n l l u)$, kichwa ${ }^{21}$

\footnotetext{
18 Más información sobre esta herramienta en: https://github.com/hinantin/QuechuaTTS

19 Se puede descargar la aplicación Buxü en el siguiente enlace: https://play.google.com/store/apps/details?id=pe.gob.iiap.buxu\&hl=en_US

${ }_{20}^{20}$ Se puede descargar la aplicación Kanllu en el siguiente enlace: https://play.google.com/store/apps/details?id=pe.gob.iiap.kanllughl=en US

${ }^{21}$ Se puede descargar la aplicación Llullu Wawa en el siguiente enlace: https://play.google.com/store/apps/details?id=pe.gob.iiap.lulluwawaghl=en US
}

LínguaTec, Instituto Federal de Educação, Ciência e Tecnologia do Rio Grande do Sul, Bento Gonçalves v. 5, n. 1, p. 109-136, jun. 2020. 
(Llullu Wawa), murui ${ }^{22}$ (Urue) y kukama ${ }^{23}$ (Wawa) (IIAP, 2016). Estas aplicaciones cuentan con información sobre el alfabeto de cada lengua, así como vocabulario sobre colores, parentesco, cuerpo humano, flora, fauna y expresiones básicas en la lengua indígena u originaria correspondiente. La iniciativa tiene como fin establecer estas aplicaciones como herramientas para lograr un aumento en el número de hablantes de estas lenguas indígenas u originarias y que puedan ser usados para la enseñanza de estas lenguas en la escuela o el hogar. Asimismo, el IIAP ha desarrollado aplicaciones con una temática similar para otras lenguas amazónicas como el shipibo-konibo ${ }^{24}$, el $y^{2} e^{25}$ e incluso para la variedad de quechua Lambayeque ${ }^{26}$, cuya versión aún se encuentra en desarrollo.

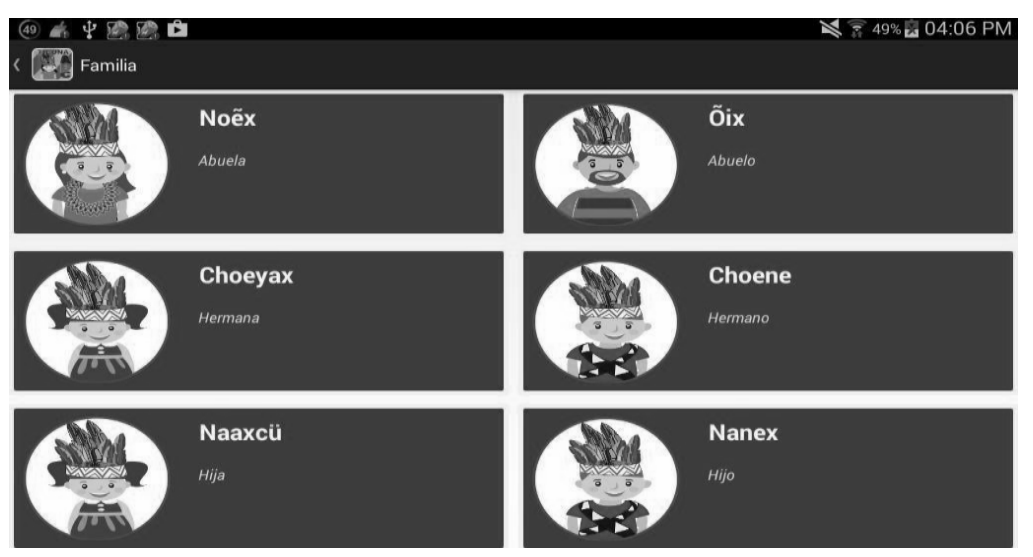

Figura 8. Sección "familia” de la aplicación en lengua ticuna (Buxü). Fuente: Instituto de Investigaciones de la Amazonía Peruana - IIAP (2016).

22 Se puede descargar la aplicación Urue en el siguiente enlace: https://play.google.com/store/apps/details?id=pe.gob.iiap.urueghl=en_US

23 Se puede descargar la aplicación Wawa en el siguiente enlace: https://play.google.com/store/apps/details?id=pe.gob.iiap.wawa\&hl=en_US

24 Se puede descargar la aplicación Shipibo-konibo en el siguiente enlace: https://play.google.com/store/apps/details?id=iiap.org.pe.yine

25 Se puede descargar la aplicación Yine en el siguiente enlace: https://play.google.com/store/apps/details?id=iiap.org.pe.yines

${ }^{26}$ Se puede descargar la versión actual de la aplicación Quechua de Lambayeque en el siguiente enlace: https://play.google.com/store/apps/details?id=pe.org.iiap.quechualambayeque 


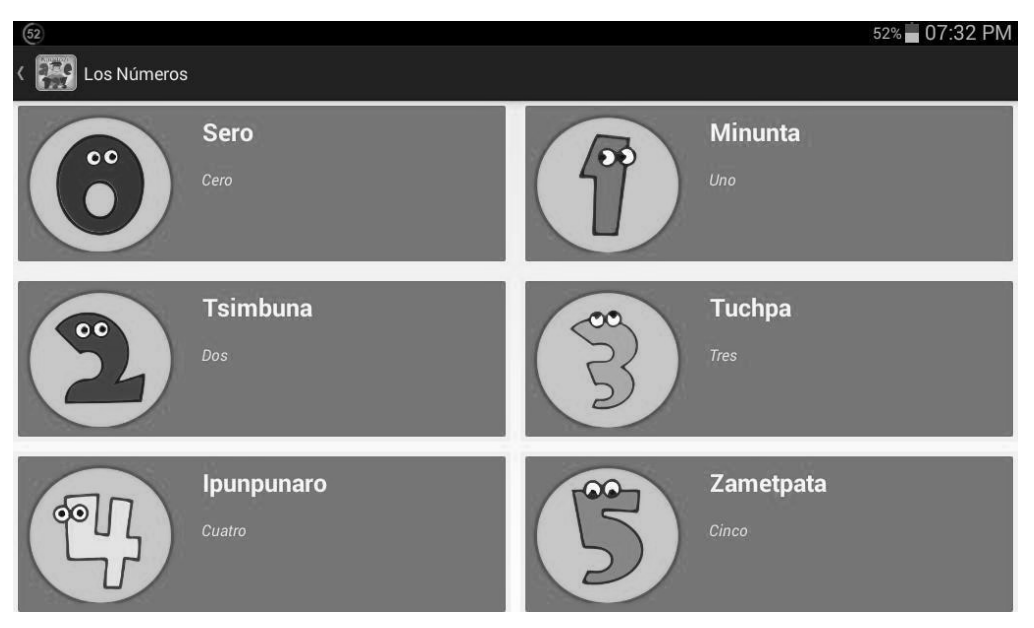

Figura 9. Sección “Números” de la aplicación en lengua kandozi (Kanllu). Fuente: Instituto de la Amazonía Peruana - IIAP (2016).

\subsubsection{Acervo digital de la cultura y lengua nomatsigenga}

La lengua nomatsigenga es una lengua amazónica hablada en el departamento de Junín, distrito de San Martín de Pangoa, zona amazónica del Perú, cuyos hablantes han elaborado en coordinación con la Universidad Nacional Federico Villarreal y el Ministerio de Cultura del Perú el Acervo digital de la cultura y lengua nomatsigenga27 como resultado del proyecto Documentación de la lengua nomatsigenga. Este acervo es el repositorio cultural y lingüístico del pueblo nomatsigenga y su objetivo es registrar, preservar y difundir la lengua y cultura. Este mismo pueblo también difunde su música a través de un canal de YouTube ${ }^{28}$.

\footnotetext{
${ }^{27}$ Se puede acceder al Acervo Digital de la Cultura y Lengua Nomatsigenga a través del siguiente enlace: http://www.nomatsigenga.com/

${ }^{28}$ Se puede acceder al canal de YouTube del Proyecto Documentación de lengua nomatsigenga a través del siguiente enlace: https://www.youtube.com/channel/UCMOL2IDjX7LOp-t LMIFNjw
} 


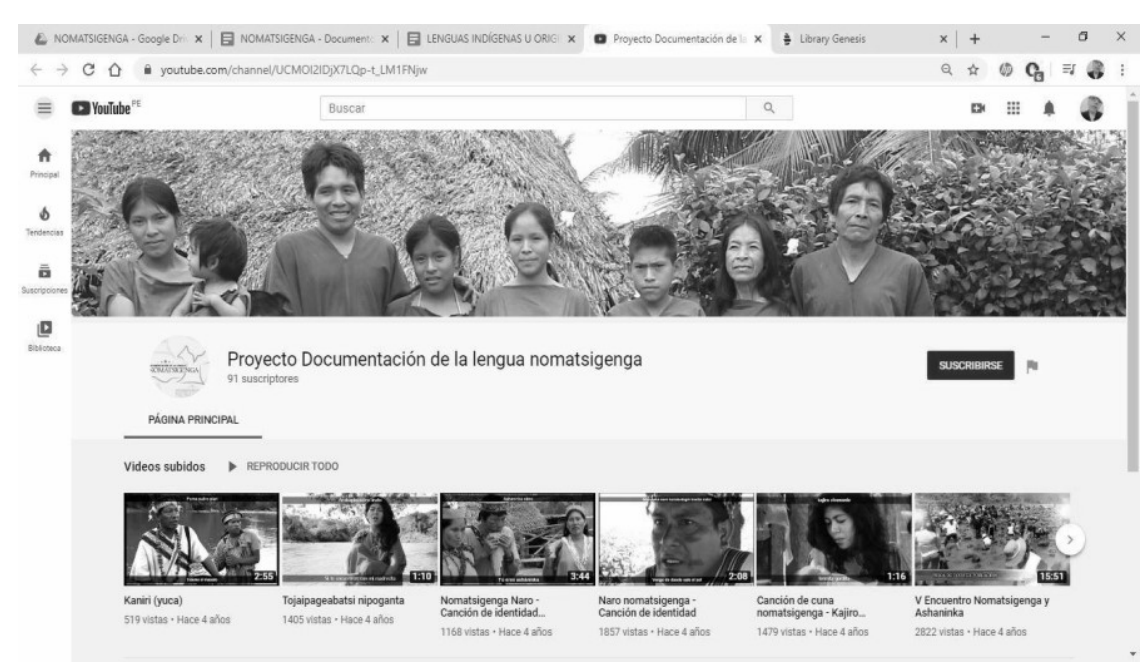

Figura 10. Canal de youtube del proyecto de documentación de la lengua nomatsigenga. Fuente: Proyecto documentación de la lengua nomatsigenga (2013).

\subsubsection{Aplicación Tsiroti}

Esta aplicación es el resultado del proyecto Documentación de la lengua nomatsigenga iniciado en 2013 y a cargo de un equipo de estudiantes de lingüística, comunicadores y profesores de la Universidad Nacional Federico Villarreal y el Ministerio de Cultura del Perú, con la finalidad de documentar la lengua y recopilar la tradición oral, canciones e información sobre plantas medicinales y otros mitos del pueblo nomatsigenga. Tsiroti cuenta con canciones e información sobre el pueblo, su lengua y su cultura ${ }^{29} 30$.

29 Se puede descargar en el Play Store la aplicación Tsiroti en el siguiente enlace: https://play.google.com/store/apps/details?id=pe.gob.cultura.tsiroti2

3o Para más información sobre la aplicación Tsiroti, puede visitar el siguiente enlace: https://www.caaap.org.pe/website/2017/07/26/tsiroti-la-aplicacion-movil-que-te-ensenaranomatsigenga-cantando/ 


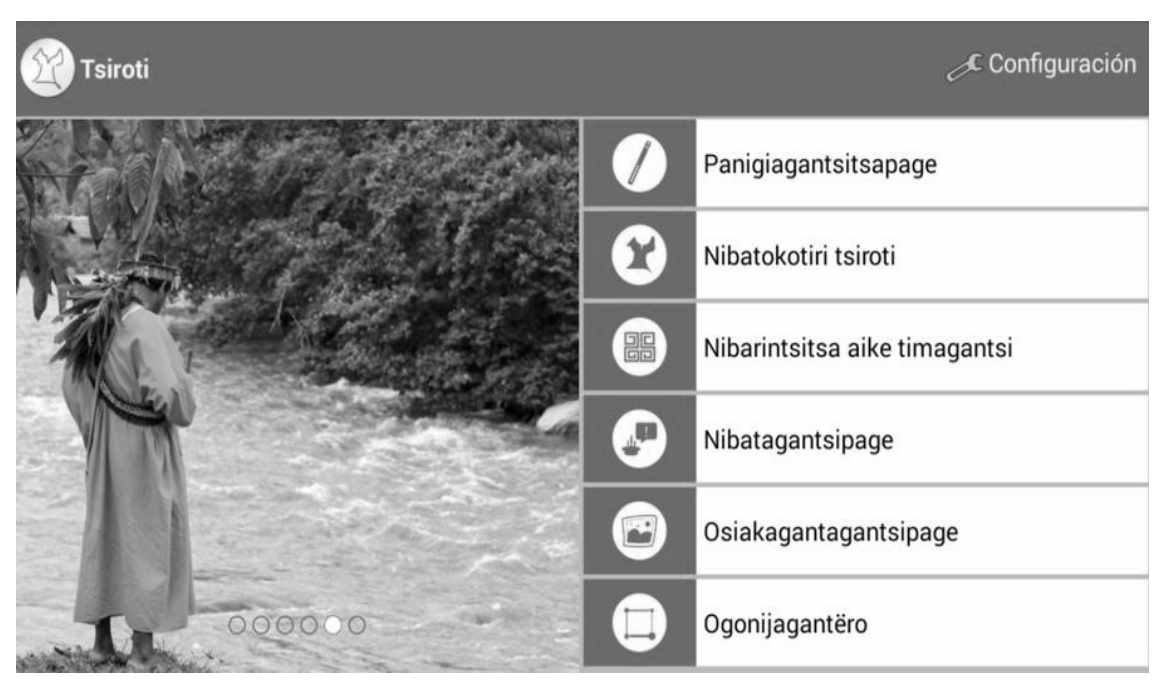

Figura 11. Aplicación Tsiroti.

Fuente: Proyecto documentación de la lengua nomatsigenga (2013).

\subsubsection{Talking Dictionaries}

\section{Living Tongues Institute for Endangered Languages es una organización} enfocada en la investigación y documentación de lenguas en peligro de extinción. Entre otras cosas, colabora con hablantes para crear herramientas en línea para el aprendizaje de lenguas y para la preservación de estas con el proyecto Talking Dictionaries ${ }^{31}$ ("diccionarios parlantes"). Se trata de una herramienta interactiva que permite a los usuarios escuchar y grabar audios de palabras y frases en alta calidad, creando así un lugar en el ciberespacio donde se puede preservar información lingüística de las distintas lenguas en peligro.

En 2007 se lanzó un software para ordenadores y en 2019 el instituto lanzó la aplicación para celulares de la plataforma. Desde el primer lanzamiento, la institución ha colaborado con hablantes de distintas lenguas en peligro de extinción alrededor del mundo para crear más de 120 diccionarios. Es así como se pueden encontrar en la plataforma diccionarios de acceso público de las lenguas quechua (variedad chanka), uitoto y yanesha, 3 de las 48 lenguas indígenas u originarias del Perú. Cada diccionario cuenta con un número de entradas en la lengua originaria, y cada entrada se compone

31 Se puede acceder a la plataforma Talking Dictionaries a través del siguiente enlace: https://talkingdictionaries.app/ 
de un audio y la palabra escrita, el significado correspondiente en inglés y español y el campo semántico al que pertenece dicha entrada.

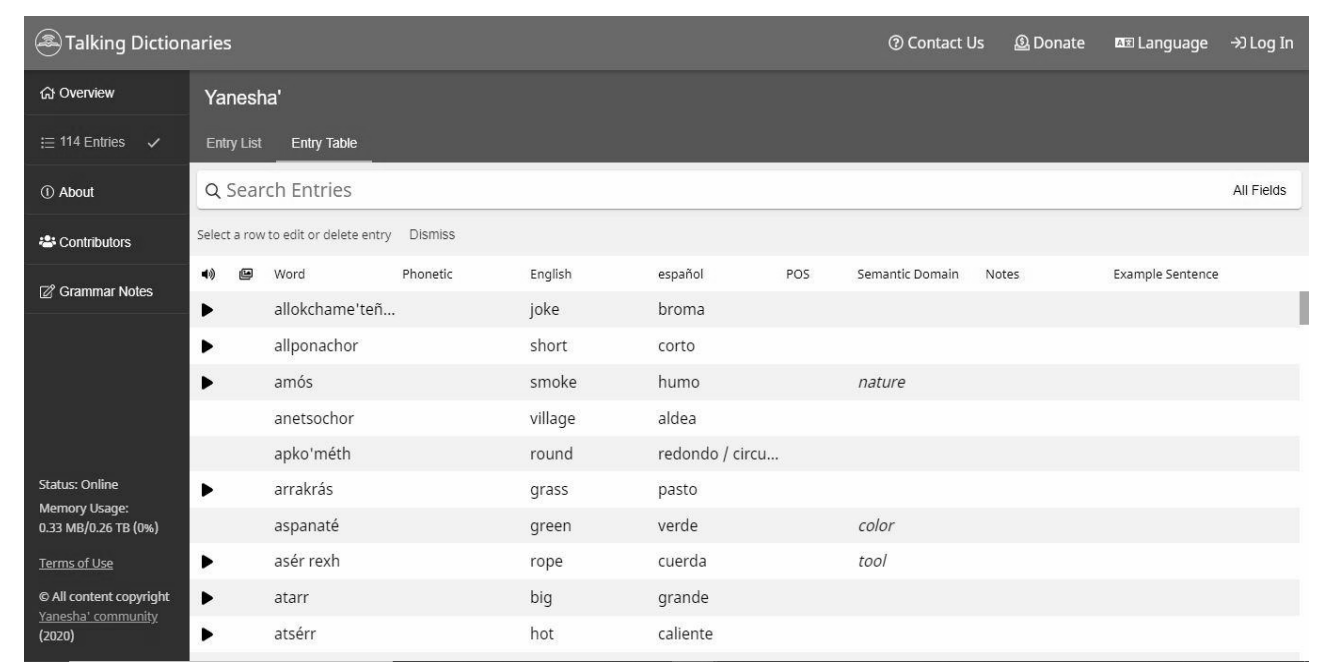

Figura 12. Diccionario yanesha en la plataforma Talking Dictionaries.

Fuente: Living Tongues Institute for Endangered Languages (2007).

3.3 Iniciativas de los propios hablantes

\subsubsection{Shumaq Willanakuy}

La plataforma Activismo Digital de Lenguas Indigenas ${ }^{22}$ es una comunidad de usuarios en línea que mapea las iniciativas tecnológicas y digitales que buscan promover y revitalizar lenguas indígenas u originarias de América Latina, así como conectar a proyectos que comparten metas similares o que están trabajando con la misma lengua indígena u originaria. En esta plataforma se encuentran identificadas algunas iniciativas peruanas, como Shumaq Willanakuy, proyecto liderado por Margot Camones Maguiña, que comenzó en el año 2014. Se trata de un programa de televisión transmitido por señal abierta, televisión por cable y YouTube, además de encontrarse en redes sociales, como Facebook33. Su objetivo es enseñar a niños y adultos el idioma quechua en su variedad ancashina a través de artículos y lecciones sencillas, con énfasis

\footnotetext{
${ }^{2}$ Se puede acceder a la plataforma Activismo Digital de Lenguas Indigenas a través del siguiente enlace: https://rising.globalvoices.org/lenguas/

33 Página de Facebook de Shumaq Willanakuy. https://www.facebook.com/shumaqwillanakuy/
} 


\section{LIINGUATEC}

en la escritura y así generar conciencia sobre el valor de la lengua entre la comunidad quechuahablante.

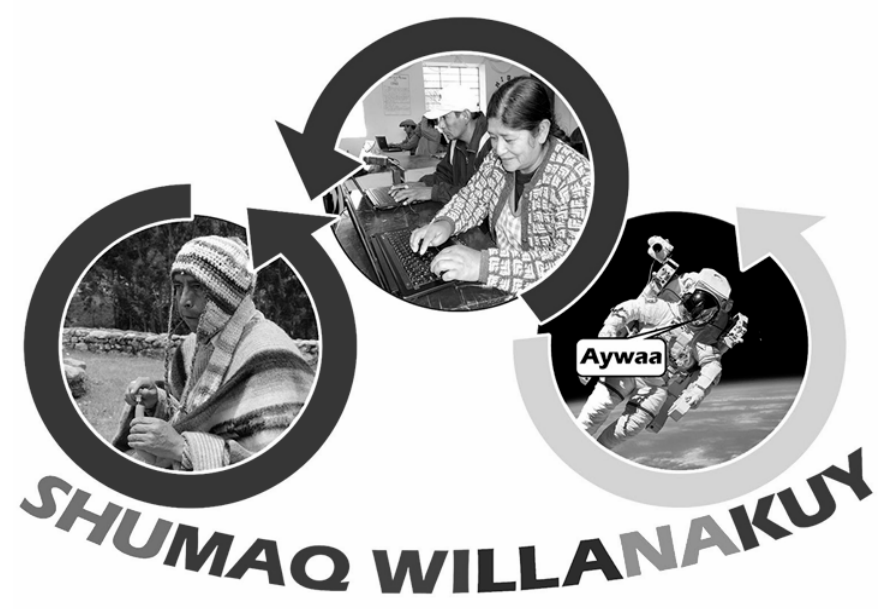

Figura 13. Logo del programa Shumaq Willanakuy. Fuente: Activismo digital de lenguas indigenas.

\subsubsection{Quechua Memes}

Otra iniciativa identificada en la plataforma Activismo Digital de Lenguas Indígenas es la página de Facebook Quechua Memes, liderada por Marisol Mena Antezana. La iniciativa también de una cuenta en Twitter e Instagram y un canal de Youtube a través de los cuales también se difunde contenido en lengua quechua. El contenido principal se publica en Facebook ${ }^{34}$ y se trata de memes que cuentan con imágenes de distintos contextos. En un inicio, el proyecto publicaba solo contenido en quechua chanka, pero luego se empezó a añadir una traducción al español de manera que las personas que no hablaban quechua pudieran aprender vocabulario básico y frases cortas. Posteriormente, el proyecto lanzó una campaña para promover la participación de sus seguidores por medio de videos y actualmente se trabaja en un contenido más audiovisual.

34 Se puede acceder a la página de Facebook de Quechua Memes a través del siguiente enlace: https://www.facebook.com/Quechuamemes/ 


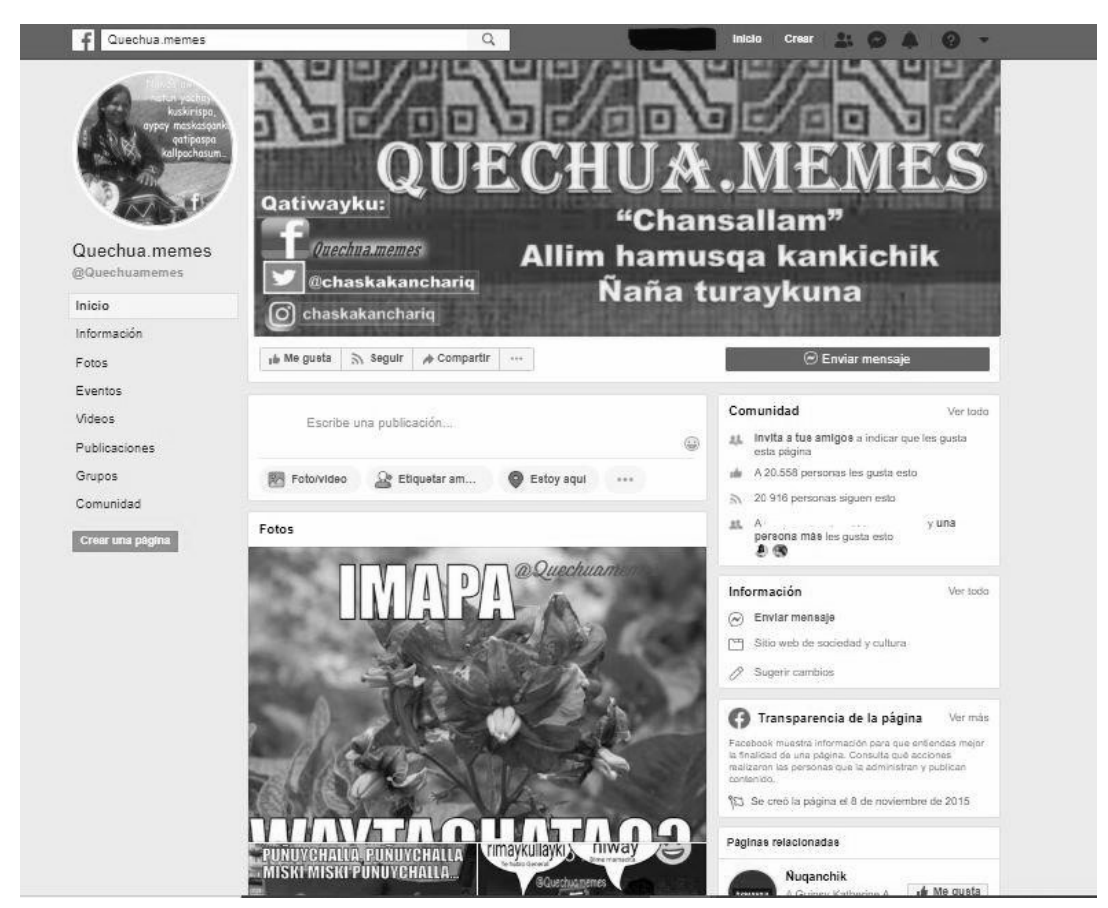

Figura 14. Página de Facebook Quechua Memes Fuente: Quechua Memes

4 Breve evaluación

En este artículo se identificaron 12 iniciativas de presencia de lenguas indígenas u originarias peruanas en internet, de las cuales el $42 \%$ se refiere a páginas web: Mapa Sonoro Estadístico de las Lenguas Indigenas y Originarias, Diccionarios Virtuales al Bicentenario, Traductor morfológico quechua-castellano, PerúEduca y Talking Dictionaries, el 33\% a aplicaciones: Uyariy, Habla Quechua, las aplicaciones en lenguas amazónicas desarrolladas por la IIAP y Tsiroti, mientras que el $24 \%$ corresponde a plataformas que involucran más de una herramienta tecnológica, ya sea un conjunto de páginas web, redes sociales y canales de YouTube: el Acervo Digital de la Cultura y Lengua Nomatsigenga, el programa Shumaq Willanakuy y la página Quechua Memes. Estos datos se señalan a continuación en el Gráfico 1. 


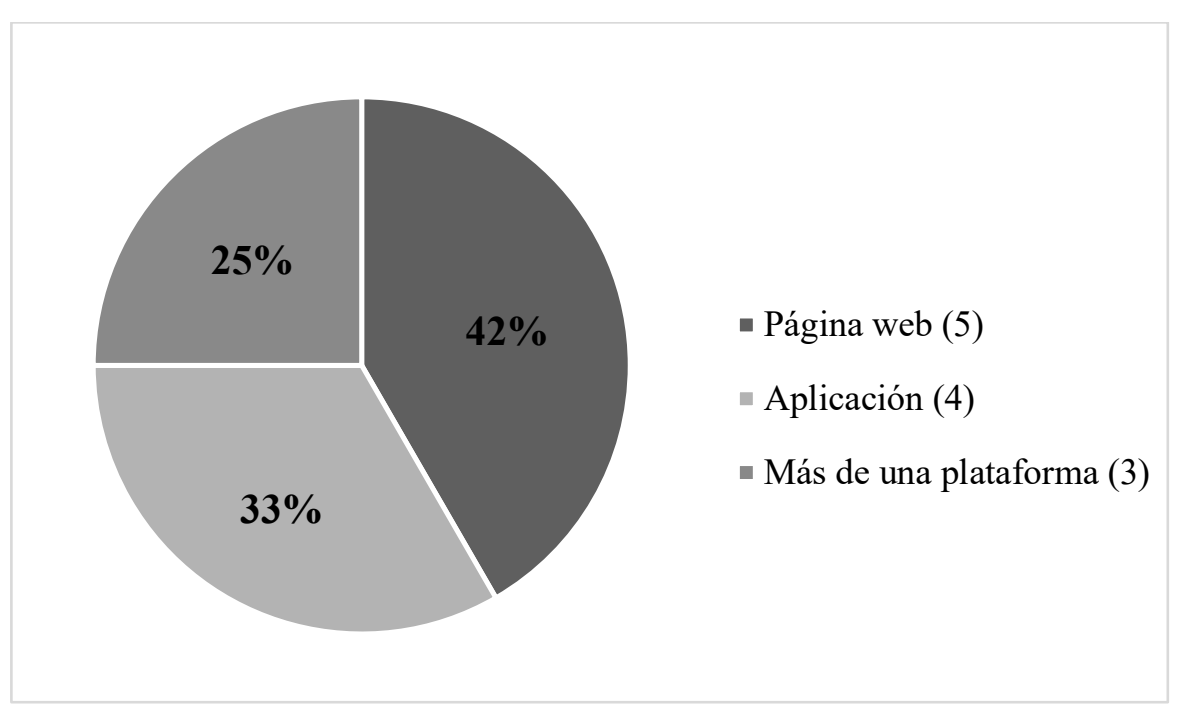

Gráfico 1 . Porcentaje de iniciativas de presencia de lenguas indígenas u originarias peruanas en internet según el tipo de plataforma.

Fuente: Elaboración de los autores.

Asimismo, en el Gráfico 2 se analiza las iniciativas en cuanto estas se encuentren en una lengua andina o amazónica. Se denomina a una lengua originaria andina si es hablada predominantemente en la zona de los andes peruanos, como es el caso del quechua, el aimara, el jaqaru y el kawki, y amazónica si es hablada predominantemente en la zona amazónica del Perú, como el ashaninka, el shipibokonibo, el matsigenka u otra de las 44 lenguas originarias restantes. El $42 \%$ se refiere a iniciativas para lenguas andinas: Uyariy, Habla Quechua, Traductor morfológico quechua-castellano, el programa Shumaq Willanakuy y la página Quechua Memes, el 33\% a iniciativas para lenguas amazónicas: Diccionarios Virtuales al Bicentenario, las aplicaciones en lenguas amazónicas desarrolladas por la IIAP, el Acervo Digital de la Cultura y Lengua Nomatsigenga y Tsiroti, y el $25 \%$ a iniciativas tanto para lenguas andinas como amazónicas: Mapa Sonoro Estadístico de las Lenguas Indígenas y Originarias, PerúEduca y Talking Dictionaries. Es importante resaltar que la mayoría de las iniciativas están destinadas a la lengua quechua por ser la lengua indígena u originaria más hablada del Perú. 


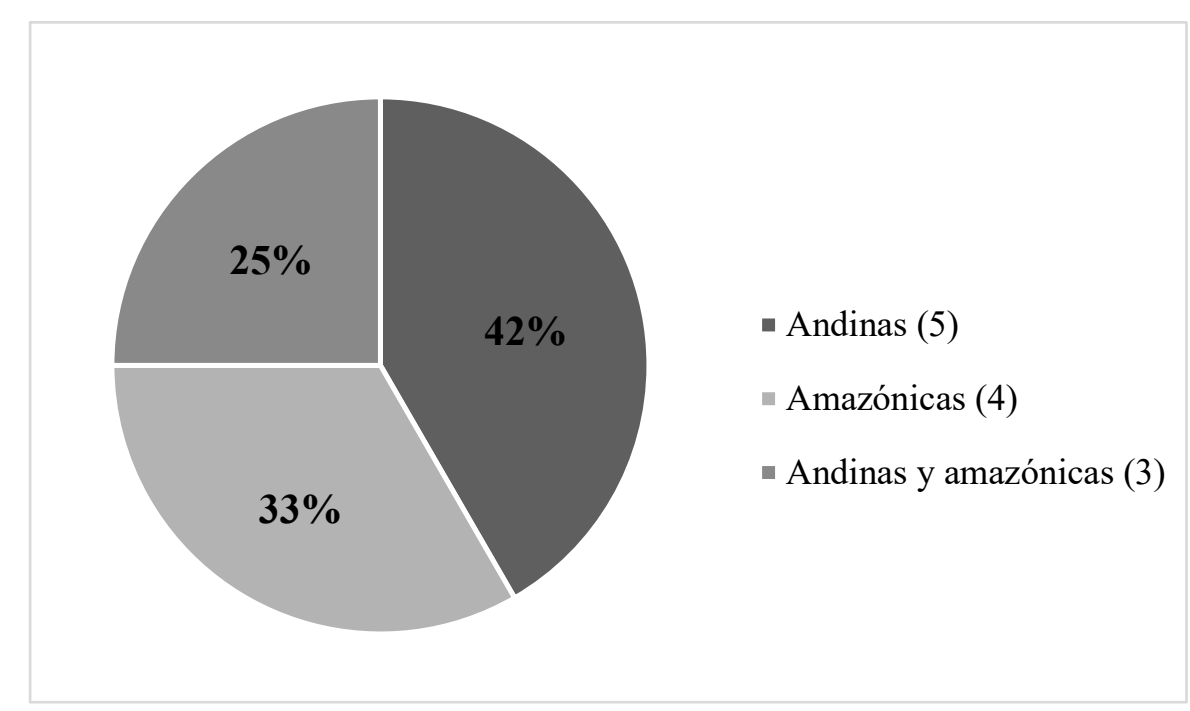

Gráfico 2. Porcentaje de iniciativas de presencia de lenguas indígenas u originarias peruanas en internet según la lengua.

Fuente: Elaboración de los autores.

De las 12 iniciativas identificadas, 40\% son iniciativas del sector público: Mapa Sonoro Estadístico de las Lenguas Indígenas, Uyariy, Habla Quechua, Diccionarios Virtuales al Bicentenario y PerúEduca; 40\% son iniciativas del sector privado: Traductor morfológico quechua-castellano, las aplicaciones en lenguas amazónicas desarrolladas por el IIAP, el Acervo digital de la cultura y lengua nomatsigenga, Tsiroti y Talking Dictionaries, y $20 \%$ son iniciativas surgidas por el interés de los propios hablantes, sin apoyo del sector público o privado, como el programa Shumaq Willanakuy y la página Quechua Memes. Igualmente, es importante resaltar que las instituciones que lideran esta clase de iniciativas son el Ministerio de Cultura, el Ministerio de Educación y el Ministerio de Comercio Exterior y Turismo, a través de PROMPERÚ, instituciones pertenecientes al sector público peruano. No es posible asegurar con fidelidad que en las iniciativas públicas o privadas no haya ningún miembro hablante de lenguas indígenas u originarias que forme parte del proyecto; sin embargo, se hace distinción debido al papel preponderante en el que se han destacado en las iniciativas. Para mayor detalle, los datos se señalan a continuación en el Gráfico 3. 


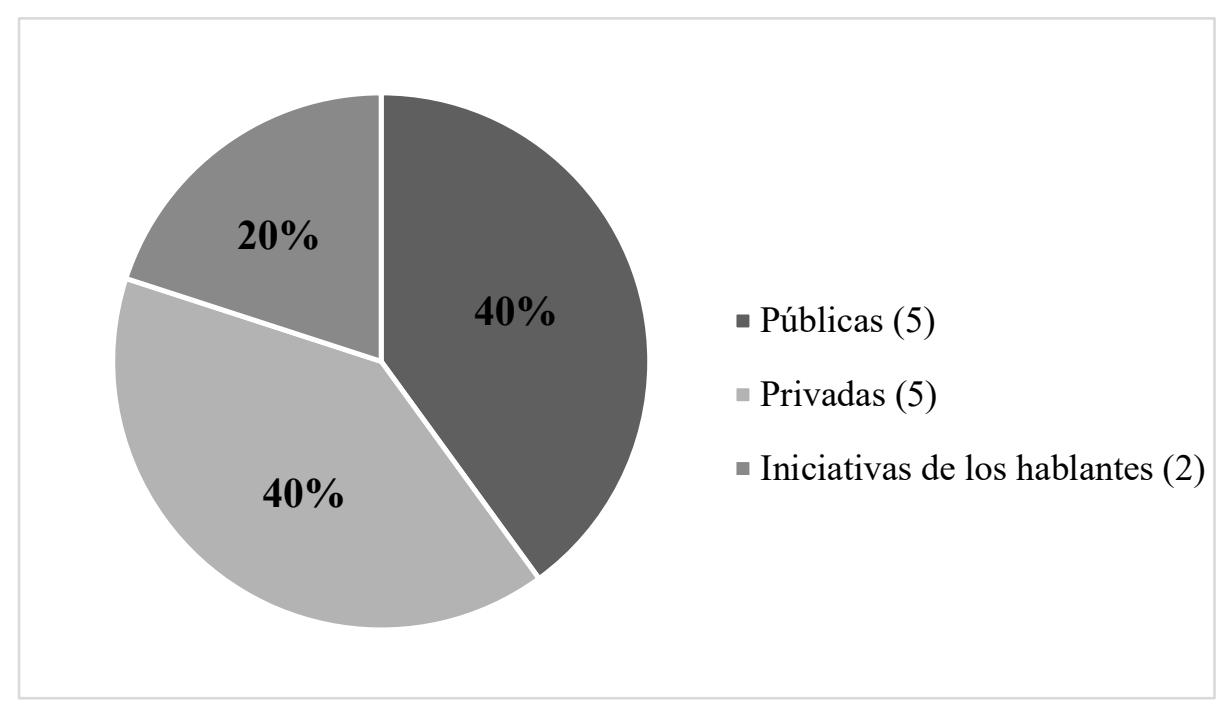

Gráfico 3. Porcentaje de iniciativas de presencia de lenguas indígenas u originarias peruanas en internet según el sector promotor.

Fuente: Elaboración de los autores.

Finalmente, 9 de las 12 iniciativas son sostenibles actualmente, es decir, siguen funcionando y se encuentran en constante actualización: Mapa Sonoro Estadístico de las Lenguas Indigenas y Originarias, Uyariy, Habla Quechua, las aplicaciones en lenguas amazónicas desarrolladas por la IIAP, Tsiroti, PerúEduca, Talking Dictionaries, el programa Shumaq Willanakuy y la página Quechua Memes, esta cifra equivale al $75 \%$ del total de iniciativas. Con respecto a las 3 iniciativas restantes que representan el $25 \%$ del total (Diccionarios Virtuales al Bicentenario, Traductor morfológico quechuacastellano y el Acervo digital de la cultura y lengua nomatsigenga), hasta la fecha no es posible acceder a ellas desde la web porque están en actualización o aún se encuentran en prototipos iniciales; por lo que, en ese sentido, consideramos son menos sostenibles que las otras iniciativas mencionadas. Estas cifras se señalan a continuación en el Gráfico 4. 


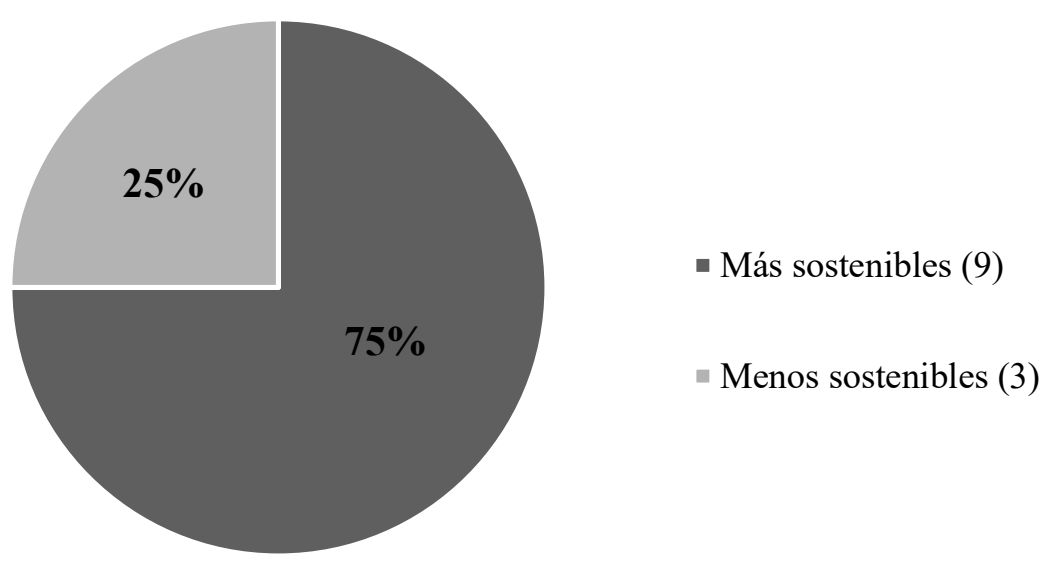

Gráfico 4. Porcentaje de iniciativas de presencia de lenguas indígenas u originarias peruanas en internet según la sostenibilidad.

Fuente: Elaboración de los autores.

Creemos que, si bien la existencia de todas estas herramientas digitales facilita el acceso y fomenta el uso de las lenguas indígenas u originarias peruanas, es necesario garantizar de forma constante la presencia de estas lenguas en el ciberespacio. DikiKidiri (2007), en un material elaborado para UNESCO, señala que para garantizar la presencia de una lengua en internet se debe tener en cuenta la elaboración de recursos: (1) lingüísticos, (2) informáticos, (3) informáticos con contenidos culturales y (4) desarrollar una comunidad de usuarios. Muchas de las lenguas indígenas u originarias peruanas se encuentran en la fase 1 , pues la mayoría de ellas ya tiene un alfabeto oficial normalizado por el Ministerio de Educación del Perú. En cambio, existen aún pocos recursos informáticos en lenguas peruanas, fase 2 , exceptuando el caso del quechua y otras iniciativas aisladas.

Esto se debe a que, a pesar de lo que señala Crystal (2006: p. 221) respecto al bajo costo que implica la creación de páginas web, muchas organizaciones no cuentan con los recursos económicos necesarios para elaborar y finalizar iniciativas de este tipo, como en el caso las aplicaciones. Paolillo (citado en DANET y HERRING, 2007, p. 424) es quien reconoce el costo de estas iniciativas para los casos de las regiones diversas lingüísticamente, como lo es Perú. Además, muchas comunidades originarias no cuentan con servicios de internet o dispositivos tecnológicos debido a su ubicación rural 
y/o a su situación económica, por lo que estas iniciativas quedan al acceso de un sector reducido de la población total que habla alguna de estas lenguas originarias.

Por último, las fases 3 y 4 aún están en proceso de desarrollo y, si bien falta bastante camino por recorrer con respecto a la presencia digital de las lenguas indígenas u originarias peruanas, la creación de comunidades virtuales en estas lenguas en un espacio tan dinámico como internet es sumamente importante. En línea con lo señalado por Martinez y Valdez (2014, p. 128) y Herring (citado en DANET y HERRING, 2007, p.7), siempre que se cuente con herramientas tecnológicas y lingüísticas funcionales, las iniciativas de presencia de lenguas originarias, al menos en el caso de Perú, logran reforzar un sentido de identidad cultural y crean espacios culturales a partir de la combinación digital de textos, audios y videos.

Referencias

ACTIVISMO DIGITAL DE LENGUAS INDÍGENAS. Disponible en: https://rising.globalvoices.org/lenguas/. Acceso en: 10/04/2020.

ANDINA. AGENCIA PERUANA DE NOTICIAS. Aplicativo para atender al público en lenguas originarias será probado en Reniec, 22/2/2020. Disponible en: https://andina.pe/agencia/noticia-aplicativo-para-atender-al-publico-lenguasoriginarias-sera-probado-reniec-785906.aspx. Acceso en: 07/04/2020.

CRYSTAL, D. Language and the internet. Cambridge: Cambridge University Press, 2006.

DAIGNEAULT, A. et al. Language Sustainability Toolkit. Living Tongues Institute for Endangered Languages, Wikitongues, 2020. Disponible en: https://livingtongues.org/wp-content/uploads/2020/02/Language-SustainabilityToolkit-v3.pdf. Acceso en: 09/04/2020.

DANET, B; HERRING, S. (Ed.) The Multilingual Internet. Language, culture, and communication online. Nueva York: Oxford University Press, 2007. 
DIKI-KIDIRI, M. Cómo garantizar la presencia de una lengua en el ciberespacio. París: UNESCO, 2007.

DIRECCIÓN DESCONCENTRADA DE CULTURA DE CUSCO. Cultura Cusco presentó diccionario enciclopédico virtual de la lengua yine yami, 24/05/2017. Disponible en: https://www.culturacusco.gob.pe/noticia/imagen/cultura-cusco-presentodiccionario-enciclopedico-virtual-de-la-lengua-yine-yami/. Acceso en: 07/04/2020.

ETHNOLOGUE, LANGUAGES OF THE WORLD. Disponible en: https://www.ethnologue.com/. Acceso en: 05/04/2020.

LIVING TONGUES INSTITUTE FOR ENDANGERED LANGUAGES. Talking Dictionaries, 2007. Disponible en: https://talkingdictionaries.app/

LLANES, G. Apropiarse de las redes para fortalecer la palabra. Una introducción al Activismo Digital de Lenguas Indigenas en América Latina. Leiden: Global Voices, 2016.

INSTITUTO DE INVESTIGACIONES EN LA AMAZONÍA PERUANA (IIAP). Revista digital $/ / A P, \mathrm{n}^{\circ} 3,2016$. Disponible en https://sinia.minam.gob.pe/documentos/revista-digitaliiap-ndeg-

HINANTIN. Traductor morfológico quechua - castellano, 2015. Disponible en: http://hinant.in/tts.html

MARTINEZ, C; VALDEZ, J. Las lenguas indígenas mexicanas en internet: análisis webométrico. Lenguas y Literaturas Indoamericanas, $\mathrm{n}^{0}$ 17, p. 122- 144, 2014.

MINISTERIO DE CULTURA DEL PERÚ. Base de Datos de Pueblos Indigenas u Originarios. Disponible en: https://bdpi.cultura.gob.pe/pueblos/nomatsigenga. Acceso en: $10 / 04 / 2020$.

MINISTERIO DE CULTURA DEL PERÚ. Mapa Sonoro Estadístico de las Lenguas Indigenas $y$ Originarias. Disponible en: https://geoportal.cultura.gob.pe/mapa/perfil/lenguas. Acceso en: 10/04/2020. 
MINISTERIO DE CULTURA DEL PERÚ. Voces vivas, estrategia de atención a lenguas indígenas en situación críticas. Lima: Ministerio de Cultura, 2018.

MINISTERIO DE EDUCACIÓN DEL PERÚ. Lenguas Originarias del Perú. Lima: Ministerio de Educación, 2018.

MINISTERIO DE EDUCACIÓN DEL PERÚ. PerúEduca. Disponible en: http://www.perueduca.pe/inicio. Acceso en: 10/04/2020.

PERÚ 21. Día Internacional de la Lengua Materna: Reniec probará aplicativo que atenderá en lenguas originarias, 21/02/2020. Disponible en: https://peru21.pe/peru/dia-internacional-de-la-lengua-materna-reniec-probaraaplicativo-que-atendera-en-lenguas-originarias-noticia/?ref=p21r. Acceso en: $07 / 04 / 2020$.

PROYECTO DOCUMENTACIÓN DE LENGUA NOMATSIGENGA. Acervo digital de la cultura y lengua Nomatsigenga, 2013. Disponible en: http://www.nomatsigenga.com/

PROYECTO DOCUMENTACIÓN DE LENGUA NOMATSIGENGA. Tsiroti, 2017. Disponible en: https://play.google.com/store/apps/details?id=pe.gob.cultura.tsiroti2

MINISTERIO DE COMERCIO EXTERIOR Y TURISMO (MINCETUR). PROMPERÚ gana premio App Innovation por aplicación móvil 'Habla Quechua', 12/11/2015. Disponible en: $\quad$ https://www.mincetur.gob.pe/promperu-gana-premio-app-innovation-poraplicacion-movil-habla-quechual

QUUECHUA MEMES. Disponible en: https://www.facebook.com/Quechuamemes/

UNESCO. Atlas UNESCO de las lenguas del mundo en peligro. Disponible en: http://www.unesco.org/new/es/culture/themes/endangered-languages/atlas-oflanguages-in-dangerl. Acceso en: 05/04/2020.

UNESCO. Declaración Universal de la UNESCO sobre la Diversidad Cultural, 2001. Disponible en: http://portal.unesco.org/es/ev.php- 


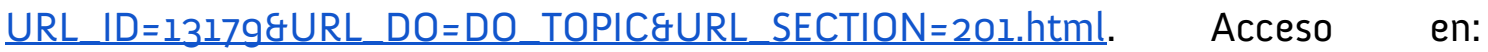
05/04/2020.

Data de submissão: 13/04/2020. Data de aprovação: 07/05/2020. 